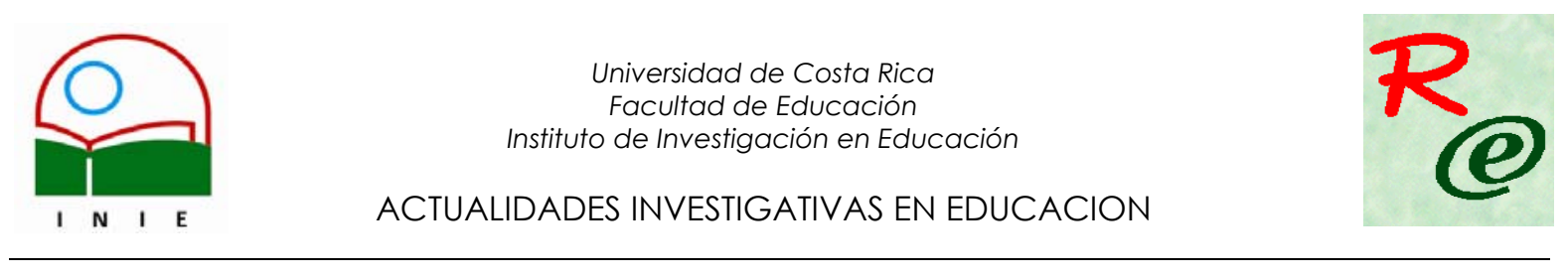

\title{
TECNOLOGÍA DIGITAL: REFLEXIONES PEDAGÓGICAS Y SOCIOCULTURALES
}

\begin{abstract}
Victoria González García ${ }^{1}$
Resumen: El mundo se encuentra en un cambio de época, entre la "era del industrialismo" y la "era de la información", entendiendo ésta última como la era de la alta tecnología y de su conocimiento práctico. En esta transición corresponde a las personas vivir un momento histórico en donde tres visiones de mundo (la contextual, la tecnológica o mecánica y la económica) se encuentran en conflicto. En los próximos años uno de estos tres paradigmas prevalecerá sobre los otros dos, con lo cual se hace necesario que se revise cuidadosamente bajo cuál visión de mundo se está incorporando las tecnologías digitales en la educación, estableciendo la diferencia entre ellas y las tecnologías de la comunicación y la información así como la informática educativa.

Desde los años 80, y como producto de la revolución tecnológica, en Costa Rica se hacen esfuerzos consistentes y sistemáticos por introducir la tecnología digital en los procesos educativos, siendo la teoría construccionista del Dr. Seymour Papert de gran influencia en este proceso.

Palabras clave: TECNOLOGÍA DIGITAL/ CAMBIO DE ÉPOCA/ INFORMÁTICA EDUCATIVA/ ERA DE LA INFORMACIÓN/

Abstract: The world is experimenting an edge change between the "industrial edge" to the "information edge", that means the edge of high technology and its practical knowledge. In this transition people are living an historical moment in witch three paradigms (the contextual, the technocratic o mechanic and the economic) are in conflict. One of these paradigms will overlook over the two others in next years so is necessary to analyze carefully in witch paradigm technologies are incorporated in educational context, making difference with communication and information technologies and computer learning.

Since 80's years, because the technological revolution, in Costa Rica are made consistent and systematical efforts by introducing digital technology in educational process, with the influence of Seymour Papert's constructivism ideas.
\end{abstract}

Key words: DIGITAL TECHNOLOGY/ EDGE CHANGE/ COMPUTER LEARNING/INFORMATION EDGE/

\section{Una época que inicia...}

La época en que crecimos y en que crecieron nuestros padres y madres está terminando. Ésta, como cualquier otra, se desarrolló "bajo la influencia una visión de mundo y de un paradigma tecnológico asociado a un modo de desarrollo dominante" (Meoño, 2003, p. 33).

\footnotetext{
1 Magíster Scientae en Psicopedagogía, Licenciada en Administración Educativa y Bachiller en Educación Preescolar. Desde 1999 se desempeña como Directora del Centro Infantil Laboratorio de la Universidad de Costa Rica, Sede Rodrigo Facio. Docente de Educación Preescolar durante 10 años en el Ministerio de Educación Pública y docente e investigadora de la Universidad de Costa Rica. Actualmente coordina el Trabajo Comunal Universitario: Innovaciones y Apoyo Pedagógico en la Comunidad Salesiana Don Bosco y la Investigación del Instituto de Investigaciones en Educación: La Educación Preescolar en la Era Digital: Retos y Desafíos.
}

Correo Electrónico: vgonzale@cariari.ucr.ac.cr

Artículo recibido: 9 de mayo, 2005

Aprobado: 27 de junio, 2005 
El problema no es que estemos viviendo "una época de cambios" sino "un cambio de época". No se trata de cualquier tipo de cambio, sino de un cambio histórico que lleva consigo cambio de ideas, de técnicas y de instituciones. Desde la perspectiva de las ideas se pasa de un sistema de ideas dominante y universal para interpretar y actuar en el mundo a otro sistema de ideas que pretende ser también dominante y universal. El cambio que estamos viviendo se da entre la tecnología de la época industrial que se basó en la mecánica, química y eléctrica y un nuevo sistema con nuevas técnicas (Ordóñez, 2004, p. 8)

Desde el año 1500 la visión de mundo era una visión orgánica asociada al modo de desarrollo medieval; agrarianismo, y a esta visión de mundo correspondía un paradigma tecnológico orgánico también dominante. Hace más de dos siglos, esta visión orgánica fue reemplazada por la visión mecánica de mundo asociada al modo de producción moderno: industrialismo $\mathrm{y}$, a esta visión de mundo corresponde un paradigma tecnológico mecánico igualmente dominante. (Meoño, 2003, p. 33)

Actualmente se gesta la sustitución del industrialismo, lo cual nos permite afirmar que estamos ante un cambio de época y NO ante una época de cambios. Es decir, al igual que hace 500 años y hace 250 años, nuestro entorno (y el de todo el planeta) se está transformando en forma cualitativa y simultánea, específicamente en las relaciones de producción, las relaciones de poder y las formas de la experiencia humana y cultura (Mato, citado por Meoño, 2003, p. 32).

La nueva época se impone a todos y todas por igual, somos vulnerables, entramos en crisis -parte de una crisis más amplia-, la crisis no es exclusiva de un sólo país, un sólo grupo, una sola institución o unas cuantas personas. Hablamos de una crisis de todo el planeta, de continentes, de naciones, de organizaciones, de grupos sociales y de ciudadanos, pues ahora, todos y todas somos ciudadanos y ciudadanas de nuestra aldea pero a la vez ciudadanos planetarios. (Ordóñez, 2004, p. 11)

Esta situación se torna aún más compleja, al analizar sus implicaciones, porque estos cambios siempre son "confusos e incontrolados" y, en los cuales, debido a la vulnerabilidad que siente, "el ser humano busca refugio en la religión, la ética, el territorio, las redes de la 
computación, el postmodernismo, el espíritu nacional, el individualismo, la delincuencia, etc." (Ordóñez, 2004, p. 7).

Los cambios de época no son una novedad para la humanidad; "el último cambio histórico ocurrió hace más de 200 años, cuando la Revolución Industrial condujo a las sociedades desde el agrarianismo hacia el industrialismo, generando incertidumbre, discontinuidad, inestabilidad, desorientación, inseguridad, perplejidad y, por lo tanto, vulnerabilidad". Ahora, tres revoluciones - sociocultural, tecnológica y económicaestán haciendo obsoleta la época del industrialismo y forjando la época del informacionalismo. Sin embargo, este proceso no ocurre de forma clara ni sin contradicciones, que son propias de un cambio de época, por la competencia entre visiones de mundo en conflicto que intentan prevalecer en la época emergente. (De Souza, 2001, p. 1$)^{2}$

Y, en este cambio de época, "la tecnología de la información está generando un nuevo modo de desarrollo y un diferente modo capitalista de producción, de experiencia y de poder" (Ordóñez, 2004, p. 6).

El actual cambio de época se gesta en los últimos 50 años, a partir de tres revoluciones: la sociocultural, la tecnológica y la económica, y estas nos llevan, a gran velocidad, hacia la nueva época que se inicia, en la cual la información será el poder y "cuyos impactos cruzados (no necesariamente compatibles entre sí), están cambiando el sistema de ideas, el sistema de técnicas y la institucionalidad de la época histórica del industrialismo" (De Souza, 2001, p. 2.).

La sociedad actual, según Castells (2005a), se moldea bajo la lógica de "sociedad en Red" como una nueva forma de organización social. No una simple etiqueta para un fenómeno tecnológico, sino una sociedad en la cual la identidad personal se define a partir de la conexión a una red, antes que por la ubicación dentro de una familia, clan, tribu o estado. ${ }^{3}$ Las sociedades, para Castells, están siendo estructuradas a partir de la complemetariedad bipolar de Red y Ego. "Las redes al comando" expresa De Souza (2003b, s.p.).

\footnotetext{
${ }^{2}$ El resaltado es personal.

${ }^{3}$ El resaltado es personal.
} 
En este contexto observamos cambios cualitativos y simultáneos en las relaciones de producción (la información será insumo y producto a la vez), en las relaciones de poder (poder sin fronteras representado por las grandes transnacionales de acumulación de capital), en las formas de experiencia humana (los movimientos sociales surgidos en defensa de la sostenibilidad del planeta, de la justicia y de la equidad) y en la cultura (la realidad virtual, el "octavo continente" de la generación.com).

Castells (2005a, s.p.) sintetiza lo anterior de la siguiente manera: "En un mundo de flujos globales de salud, poder e imágenes, la búsqueda de la identidad colectiva o individual, asignada o construida, se vuelve la fuente fundamental del sentido social". Y debido a la prevalencia actual de la tecnología de la información, el mundo está siendo quebrado entre una tecno-elite, globalmente conectada, y las identidades comunitarias, atrincheradas en lo local. Castells destaca la importancia del moderno proceso de localización, a la par de la globalización.

Todos estos cambios simultáneos producen sensaciones como inestabilidad, desorientación, incertidumbre, inseguridad y como consecuencia vulnerabilidad tanto en las personas y como en las organizaciones (entre ellas las educativas). No es un secreto para nadie que actualmente la sociedad se siente vulnerable debido a las guerras, el hambre, la velocidad de la información y de las innovaciones tecnológicas, la inestabilidad económica, ya que son características que nos hacen sentir fuera de control, como si una fuerza externa nos dirigiera y no pudiéramos hacer nada para detenerla. En el caso de la tecnología, esta situación es mucho más evidente, se desplaza más rápido que el avance generacional. En muchos casos, cuando una persona adulta recién aprende a usar un instrumento tecnológico, ya han sido inventados tres para sustituirlo, y al mismo tiempo, un niño o una niña dominan perfectamente el uso de ese instrumento.

\section{Tres revoluciones que cambian el mundo...}

El cambio en las diferentes relaciones de poder, de producción, en las formas de la experiencia humana y cultura, es producto de las tres revoluciones mencionadas anteriormente: la revolución sociocultural, la revolución económica y la revolución tecnológica. 
De Souza (2001) las define en los siguientes términos:

La revolución sociocultural, cuya premisa esencial es el respeto a todas las formas de vida y al derecho que tienen de contar con un hogar (planeta Tierra) en el futuro, se observa con los cambios en la participación social, como la incorporación de las mujeres, de las personas con alguna discapacidad, la firma de tratados y de convenciones sobre los derechos humanos; es decir, que se observa una gran tendencia de una parte de la humanidad a lograr una equidad en el acceso a las oportunidades para el desarrollo humano sostenible. Estas personas están cambiando de la época del industrialismo por una época en la que prevalezca la "preocupación por la sostenibilidad de todas las formas de vida en el Planeta", bajo una visión holística de mundo.

La revolución económica, cuya premisa esencial es que la rentabilidad económica o competitividad, es la solución para la sostenibilidad; se relaciona directamente con la llamada globalización, bajo etiquetas como reajuste estructural, reforma económica, modernización productiva, privatización, liberalización, mega-fusiones, reconversión productiva, flexibilidad laboral, dolarización de las economías nacionales, integración regional y fondos competitivos. Esta revolución orienta el cambio del industrialismo hacia el mercado, bajo una visión económica de mundo.

La revolución tecnológica, se fundamenta en la premisa de que la tecnología digital es la solución para el desarrollo de los pueblos, pues permite hacer mejor lo que ya se hace y es producto de la evolución de la época industrial. Esta se manifiesta en la formación de redes virtuales y en la integración electrónica de formas (texto, sonido e imagen) y medios de comunicación. La creación de oficinas-en-red, los libros virtuales, los espacios inteligentes (edificios, fábricas, oficinas y residencias, cuyas funciones básicas son manejadas por computadoras independientes de un operador humano) cambian la época del industrialismo por una época tecnológica, bajo una visión mecánica de mundo.

La visión mecánica, que impacta profundamente las otras revoluciones, ha sido la dominante durante la época anterior (el industrialismo), por tanto ha afectado directamente, y lo continúa haciendo, nuestras actividades cotidianas. Entre otras cosas nos exige ser usuarios y usuarias de las tecnologías en forma permanente, con las implicaciones que esto conlleva. Quesada (2001, p. 5), opina que 
al incorporar la nueva tecnología, se crea la necesidad de remozar habilidades, destrezas y conocimientos -recualificarnos- que nos permitan operar en este nuevo modelo. Lo cual por supuesto es controversial y deslegitima modelo dominante vigente y que vertiginosamente está cayendo en decadencia.

El acceso a la información se ha ampliado enormemente gracias al uso de las nuevas tecnologías, específicamente las utilizadas para la información y comunicación. "Por primera vez en la historia, la información es simultáneamente insumo y producto" (De Souza, 2003). Información que es cada vez más necesaria y exigida para ser del grupo de las personas incluidas en la "sociedad del conocimiento" (Castells, citado por Ordóñez, 2005).

Aunque todavía no existe consenso sobre cual será la nueva visión de mundo, EL PARADIGMA INFORMACIONAL, moldeado en gran medida por la revolución en la tecnología de la información y sus impactos en otras revoluciones tecnológicas, se perfila como el nuevo paradigma y se encuentra prácticamente establecido. (Meoño, 2003, p. 34)

En otras palabras, parece vislumbrarse una época en la que los seres humanos, para estar incluidos en las dinámicas sociales, necesitan ser capaces de analizar, recolectar, sintetizar información, elaborar hipótesis, imaginar respuestas y comunicarse. Sin embargo los mecanismos de comunicación están claramente impactados por la tecnología actual, como los teléfonos celulares, computadoras personales, red Internet (o espacios virtuales), televisores, radios, reproductores de video y sonido. Por lo tanto es necesario no solo contar con destrezas intelectuales para la comunicación, sino también con capacidad de utilizar la tecnología para comunicarse exitosamente.

Aquel o aquella que no pueda manipular instrumentos tecnológicos pierden irremediablemente una gran oportunidad de comunicación y de información. $Y$ en la época en la que la información será poder, insumo y producto, quienes no puedan hacerlo serán los excluidos en la nueva época. 


\section{Y la tecnología digital...}

Ahora bien, cualquier proceso de cambio o de innovación que se asuma, incluidos aquellos del ámbito pedagógico, están permeados al cien por cien, ya sea consciente o inconscientemente, por la visión de mundo que se asuma. $Y$ por supuesto, lo mismo sucede al analizar la tecnología digital y lo que ella significa para la sociedad costarricense. Sin embargo, hablar de tecnología digital implica comprender el concepto de tecnología y diferenciarla de las tecnologías de la información y la comunicación y de la Informática Educativa.

La tecnología es toda aquella construcción mental que modela y controla el entorno, producto de un proceso evolutivo, y que es transformada en un material o herramienta para cumplir con un objetivo o para resolver un problema. Además, no es solo la creación y el uso de la herramienta, sino que conlleva el almacenaje de los conocimientos y una progresión de la sofisticación de las herramientas. Requiere de invención y es por sí misma una continuación de la evolución a través de otros métodos ${ }^{4}$. Por ejemplo un machete, un serrucho, un carro, un teléfono, un lapicero, etc. La época industrial nos dotó de suficientes herramientas, desde grandes como un tractor, hasta pequeñas como un prensador de papel (clip) con lo cual se facilitó mucho la resolución de problemas cotidianos.

Las tecnologías de la información y la comunicación son una forma de denominar al conjunto de herramientas, habitualmente de naturaleza electrónica, utilizadas para la recogida, almacenamiento, tratamiento, difusión y transmisión de la información. Nos permiten tener al alcance la información (como bien lo dice su nombre) y que además nos permiten enviar mensaje. (Fernández, 2001) Es decir son el canal o vehículo en que viajan los mensajes que recibimos o que enviamos. Como por ejemplo la televisión, la videograbadora, la cámara fotográfica, la reproductora de video o de sonido, la red Internet, el sistema de correo electrónico. Los dos últimos ejemplos fueron durante mucho tiempo los únicos que necesitaron indispensablemente a la computadora para tener acceso a ellos. Actualmente los avances tecnológicos en el ámbito digital sorprenden y crean novedades para lograrlo, como por ejemplo un reloj y teléfono celular a la vez o un teléfono que puede enviar mensaje en tres vías: oral, escrito y por Internet, tomar fotos, y múltiples funciones.

\footnotetext{
${ }^{4}$ Recuperado el 15 de junio del 2005 de www.smartcomtec.com.mx/glosario.asp
} 
Es importante resaltar que, con las tecnologías de comunicación tradicionales la transmisión del mensaje era lineal y emisor y receptor eran claramente identificables. Las nuevas tecnologías permiten tejer "redes de comunicación" (Castells, 2005b, s.p.) que en su virtualidad parecen más a telas de araña que a canales lineales de comunicación.

Las nuevas tecnologías de la información y la comunicación son consideradas como factores de desarrollo en áreas clave como la educación, la salud y otros sectores de la actividad económica. En este sentido la convergencia de las telecomunicaciones, las computadoras y las tecnologías audiovisuales, como resultado de los progresos registrados en la tecnología digital, ha implicado un incremento radical en los flujos de información directamente accesibles debido al aumento de la capacidad de las redes y la reducción de costos. (Pichs, 2005, s.p.)

La Informática Educativa se concibe como la ciencia que integra la educación y las herramientas informáticas para enriquecer el proceso pedagógico de enseñanza aprendizaje mediante el uso de la tecnología digital. Es básicamente un abordaje curricular con el objetivo de propiciar construcción de conocimientos en los alumnos, las alumnas y personas en general, utilizando como herramienta fundamental el computador, el cual se conecta a una gran red mundial que es Internet (www.psicopedagogia.com).

Finalmente la tecnología digital tiene que ver con todos aquellos materiales o herramientas a los cuales el ser humano les incorpora, mediante un lenguaje matemático, instrucciones que se traducen en acciones para resolver un problema o desafío. Por ejemplo equipo doméstico como lavadora de ropa, licuadora, cocina, juguetes como robots, calculadoras, y obviamente todos aquellos que llevan una programación como software. Entre estos últimos existen innumerables muestras en el mercado mundial. Es importante recalcar que la tecnología digital no tiene forma de computador personal, aunque toda computadora está compuesta por tecnología digital.

Por lo tanto, todas las tecnologías de la información y la comunicación son tecnología (valga la redundancia) porque fueron creadas por el ser humano para facilitar el desafío de la comunicación entre las personas. Pero éstas no necesariamente son tecnología digital. Por ejemplo el teléfono analógico, las cámaras de fotos de rollo, la máquina de escribir eléctrica, entre otros. 
La tecnología digital en la época actual, puede ser vista desde tres prismas, dependiendo cada uno de la visión de mundo dominante.

Si se mira desde el punto de vista de la visión mecánica de mundo, es decir, bajo la metáfora de que el mundo es una máquina, la tecnología digital (computadora, juegos electrónicos, otros) viene a ser un componente programable, a través de bits, que requiere la máquina (el mundo) para que ésta sea más eficaz y produzca mejor (procesos que mantengan la máquina en funcionamientos) mediante el adiestramiento de las personas (la educación). En otras palabras, el "planeta-máquina" necesita funcionar, sin preguntarse para qué y por qué (una máquina es un objeto que no piensa), hasta que se acabe el combustible (es decir la vida en el planeta) y la tecnología ayuda para que esto se realice con menos esfuerzo físico. Desde esta perspectiva, la tecnología digital existe para la eficiencia: Hay que tener computadora (u otros instrumentos digitales) para que los procesos y productos sean de calidad y en los cuales las personas son "recursos humanos" para el mejor funcionamiento de la organización - máquina.

Bajo la visión económica de mundo, la tecnología, como parte de un mercado, se convierte en un proveedor de productos, procesos y servicios intensivos de conocimiento, para aumentar la competitividad. Desde esta perspectiva, el objetivo fundamental es la ganancia económica, aún cuando no se cuestiona en cuántas manos y a quiénes beneficia esta ganancia. Lo que importa es la acumulación de capital económico y, por lo tanto, cualquier otra persona que también tenga acumulación de capital, no es ni será un colega o un socio, será la COMPETENCIA. La tecnología digital, existe para mejorar la rentabilidad económica y el control de las finanzas: Hay que tener computadoras en la organización para competir mejor, obtener mayores ganancias al menor esfuerzo posible, humano $y$ material, y en el cual las personas somos vistas como un "capital humano" para el fortalecimiento económico de la organización.

Desde la perspectiva de la visión holística de mundo, la tecnología digital es apenas un elemento o instrumento que facilita el cambio y el desarrollo, considerando este último como el esfuerzo que hace un grupo social específico por el crecimiento colectivo. Es un recurso que sirve a las personas para organizar sus actividades; eliminar la duplicidad de funciones; minimizar el tiempo destinado a labores mecánicas, priorizar en un espacio para la construcción colectiva y la generación de propuestas de cambios sociales para la calidad 
de vida de los seres vivos del planeta, en el cual la comunicación y las interrelaciones entre las personas son vitales. Bajo esta visión de mundo los seres humanos son "ángeles de un ala que solo pueden volar abrazados" (De Souza, 2003b, s.p.). Es decir, la tecnología digital apoya el registro de nuestra propia historia - realidad: hay que tener computadoras en la organización para resguardar la información, optimizar procesos, y tener tiempo para pensar. En este sentido, las personas son "talentos humanos" que juntan sus esfuerzos para el logro de la sostenibilidad de las organizaciones $y$, por ende, de todas las formas de vida en el planeta.

La tecnología de la información ha hecho posible la creación electrónica del octavo continente del Planeta: un continente digital, donde INTERNET es un puerto virtual en la era del acceso. En este continente virtual, el tiempo histórico no cuenta, el espacio geográfico desaparece y las relaciones sociales son innecesarias. Por eso, el concepto de "red" asume consecuencias prácticas para la nueva morfología social de las sociedades avanzadas del futuro. En la Era Digital, crece de forma vertiginosa la organización de redes virtuales, que reemplazan a los contactos cara-a-cara, creando una especie de vecindario electrónico global, donde las relaciones sociales y políticas parecen innecesarias. Mientras la facilidad de acceso a la información no encuentra precedente en la historia, la futura generación punto-com corre el riesgo de asumir que ya no será necesario caminar para conocer el mundo y transformarlo. (De Souza, 2001, p. 13)

\section{Algunos hechos en la educación costarricense como producto de la revolución tecnológica...}

Es muy interesante observar como en Costa Rica, a partir del desarrollo de la revolución tecnológica, se considera vital acercar a los y las estudiantes al uso de herramientas digitales.

El proceso comienza en 1986, cuando el entonces presidente de la República, Dr. Oscar Arias Sánchez, se compromete con una renovación del sistema educativo nacional y una de sus estrategias fue la introducción de las computadoras como herramientas educativas en el ámbito escolar; para lo cual asigna al Ministerio de Educación Pública (MEP) un papel esencial y, a la vez, apoya la creación de la Fundación Omar Dengo (FOD). 
EI MEP, por su parte, asume la introducción de la informática en el sistema educativo como uno de los ejes principales para elevar la calidad de la educación y la FOD se constituye con el objetivo, entre otros, de dotar al MEP de los recursos económicos y tecnológicos necesarios para la incorporación de las computadoras en las escuelas.

En ese entonces, Costa Rica, desde el MEP, asume, por una parte, el desafío de promover una nueva generación de costarricenses "familiarizados con la tecnología", los cuales hayan iniciado sus primeras experiencias tecnológicas desde la educación preescolar, y, por otra, la necesidad de "introducir las computadoras al servicio del aprendizaje de los educandos, como un recurso para el pensamiento lógico y la creatividad en la resolución de problemas" (Badilla, 1991, p. 8.).

Actualmente gran cantidad de centros educativos preescolares en Costa Rica promueven el acercamiento a las tecnologías. Solo en la capital, San José, de 147 centros preescolares existentes (públicos y privados), 54 cuentan con el servicio de informática educativa. $^{5}$

El Centro Infantil Laboratorio de la Universidad de Costa Rica (CIL) (González, 2003), es uno de esos centros y ha desarrollado, a partir de 1999, iniciativas de incorporación de la tecnología en el aula, como herramienta para la construcción de aprendizajes significativos de los niños y las niñas preescolares, La experiencia Inicia con cinco computadoras en un salón multiuso, para que las usen niños y niñas de dos años a seis años, siendo que en esta institución se cuenta con un grupo de 18 niños y niñas, otro de 20 niños y niñas y dos de 25 niños y niñas. Se concibió al acercamiento a las computadoras como una actividad espontánea, con grupos de 10 niños y niñas en forma simultánea. Sin embargo ellos y ellas no las utilizaban porque implicaba salir del aula, dejar los otros juegos y compañeros y eso no les gustaba. Por lo tanto a partir del año 2003 las computadoras se trasladan a las aulas (una por aula) como un juguete adicional a los otros juegos que existen en las aulas.

Los resultados obtenidos a raíz de esta experiencia, muestran lo siguiente:

\footnotetext{
${ }^{5}$ Esta información es recopilada por la autora mediante entrevistas, llamadas telefónicas y visitas a los centros infantiles preescolares de San José, como parte de la investigación: "La Educación Preescolar en la Era Digital: retos y desafíos.
} 
1. Aún cuando el uso de programas como Logo, Word, Paint-brush propician la construcción de aprendizajes significativos, no responden a las necesidades de niños y niñas menores de 5 años.

2. La utilización de software educativo existente en el mercado, evidenció la necesidad de revisar y evaluar los principios epistemológicos que lo sustentan. La corta experiencia del CIL indica que este material fomenta la memorización y la respuesta automática.

3. La facilidad de computadoras no asegura que los niños y las niñas la utilicen para construir aprendizajes significativos. Los niños y las niñas menores de 3 años necesitarían material tecnológico digital que les permita construir en el nivel concreto y no tan abstracto, como en una computadora.

Así mismo, las limitaciones más importantes en este proceso han sido:

1. El tipo de software encontrado en el mercado, que no es apto para personas de tan corta edad. No se ha encontrado, hasta el momento, material que estimule el pensamiento lógico y crítico. Todo lo encontrado más bien estimula destrezas puramente mecánicas en la utilización de la computadora y adquisición de conocimientos memorísticos.

2. El mantenimiento de las computadoras, requiere dos componentes básicos. Uno, contar con una persona que haga limpiezas regulares a las máquinas, así como verificación y actualización de los sistemas antivirus y dos, asignar cierta parte del presupuesto institucional para mantener las computadoras actualizadas en lo que se refiere a sus componentes.

Por otra parte, en lo que se refiere a la informática educativa, muchos y muchas profesionales han construido conocimientos, entre los que destacan los siguientes aportes:

Zúñiga (1994, p.1), justifica una postura epistemológica (constructivismo) congruente con la filosofía del Programa de Informática Educativa, en la que evidencia que una computadora en el aula no significa nada, si esta no es un instrumento para la "construcción y reconstrucción" del ser humano, con los siguientes argumentos:

1. El constructivismo es una opción metodológica mediante la cual los "conocimientos se construyen y no se transmiten". 
2. Cada persona "construye y reconstruye", en forma permanente, el propio conocimiento de sí mismo y del mundo.

3. El conocimiento construido no puede transmitirse mecánicamente.

4. El conocimiento construido tiene como componente esencial la participación activa en el proceso.

5. El sujeto y el objeto se construyen recíprocamente.

6. Las computadoras cuestionan las ideas imperantes acerca de lo que se puede aprender y cuando.

7. El análisis debe centrarse en cuáles nuevas realidades culturales se desean producir para lograr un cambio y en cuál dirección.

Taylor, citado por González (1991, p. 31) afirma que la tecnología aplicada a la educación, se dirige hacia tres vertientes: "servir de tutor, ser un instrumento para realizar una labor con mayor eficiencia y aprender a programar la computadora para realizar una actividad determinada". Esta última enfatiza más en "la actividad del estudiante que en la tarea por realizar" lo cual ha sido la inspiración del programa conocido como LOGO WRITER.

González (1991, pp. 31-33), a su vez, afirma que "el desarrollo de la Instrucción basada en computadoras (computer - based- instruction) en educación, ha sido lento en comparación con el desarrollado en otras áreas como la economía, la medicina y otras". Y en su estudio concluye que

El ambiente de las computadoras y los programas automatizados son aspectos novedosos como medios para la enseñanza y el aprendizaje. De acuerdo con su aplicación, así serán los resultados, de ahí la necesidad de realizar investigaciones que permitan conocer más sus potencialidades reales, sus ventajas y sus desventajas. Lo anterior permitirá que los investigadores y los maestros utilicen adecuadamente las nuevas tecnologías, seleccionen con propiedad las metodologías y estrategias de enseñanza - aprendizaje y generen nuevos conocimientos en beneficio de los estudiantes. (González, 1991, p. 37)

Por su parte, en 1997 (pp. 109 - 113), Zamora manifiesta su preocupación en cuanto al uso ético que se le dé a la tecnología, considerando que 
la tecnología contemporánea satisface necesidades humanas; pero también las crea o las rediseña, cambiando los sistemas de conservación de la vida, alterando el entorno, redefiniendo a cada paso, el papel del individuo y las sociedades en los procesos productivos.

Se observa acá una preocupación sustentada en la visión holística de mundo, y se infiere la sensación de vulnerabilidad ante un entorno cambiante.

García (1997, p. 45) propone que la "informática educativa sea una opción educativa, social, cultural, política e incluso económica, para hacerle frente a las demandas de las transformaciones sociales e históricas que vivimos". Aspecto que merece la pena mencionar porque demuestra, desde la experiencia costarricense, el impacto del cambio de época actual.

Ya en el año 2003, Mikhak y Badilla (2003a) manifiestan lo siguiente:

1. La tecnología digital debe estar al servicio del ser humano en el desempeño de sus actividades cotidianas.

2. La realidad y el contexto para el cual la tecnología digital fue diseñada, no coincide con la realidad y el contexto de poblaciones en vías de desarrollo.

3. Para que el uso de la tecnología realmente apoye las estrategias de crecimiento de una comunidad, se requiere de una verdadera transformación de la tecnología. Es decir, que sea diseñada para la realidad local, producida en el contexto local. "Repensada, rediseñada y reproducida en el nivel local".

4. Para lograr esto, se hace necesario, por lo tanto "sacar la computación de las computadoras" y usarlas en la vida cotidiana, con la participación esencial de equipos interdisciplinarios.

\section{El construccionismo y algo más...}

El Dr. Seymour Papert, además de crear herramientas digitales para apoyar el aprendizaje, propuso el Construccionismo como una teoría educativa que fundamenta el uso de las tecnologías digitales en educación y que otorga a los y las alumnas un rol activo en su aprendizaje, colocándolos como diseñadores de sus propios proyectos y como constructores de su propio aprendizaje (Badilla y Chacón, 2004, p. 4.). 
En la teoría construccionista de Papert, se encuentran implícitos, entre otros, tres conceptos instrumentales para brindar a los y las estudiantes las mejores oportunidades de construcción:

1. objetos con los cuales pensar: objeto o idea utilizada para pensar sobre otras cosas, utilizando para ello, la propia construcción de dicho objeto,

2. entidades públicas: es el objeto o idea para pensar compartido con los demás, transformado en una organización pública y un reforzador del aprendizaje construccionista;

3. micromundos: una entidad pública (problema cotidiano) que utiliza como herramientas para su construcción objetos para pensar y que representa una realidad; brinda herramientas para la exploración y es una parte inherente de la construcción del conocimiento (Badilla y Chacón, 2004, pp. 6-10). Por ejemplo, un objeto con el cual pensar puede ser un problema cotidiano como adornar algunas zonas del aula, la entidad pública puede ser el socializar ese reto y buscar la solución en grupo y lograr el reto, que en el caso de micromundos es una herramienta digital que permite visualizar ese proceso vivido.

Ordóñez (2004, p. 1) plantea que la tecnología y las máquinas son una "caja negra" de alto conocimiento que no necesariamente hay que conocer para controlar y, por ende el conocimiento que empieza a ser buscado por las nuevas generaciones, es el conocimiento práctico, aquel que funciona para obtener información, considerando que actualmente la información es poder. "Nos ha tocado vivir en "la era de la información", que es lo mismo que decir, en la era de la alta tecnología y de su conocimiento práctico".

La presencia de las tecnologías de la información y la comunicación en los diversos niveles y modalidades de la educación, no solamente es una realidad bastante aceptada al iniciar el siglo XXI, sino que apunta a multiplicarse, y a llegar cada vez a mayores y más diversas poblaciones. La tendencia general es, sin embargo, que estas tecnologías sean incorporadas a los procesos de aprendizaje, no como un medio para la construcción del conocimiento, sino como un fin en sí mismo (Badilla y Chacón, 2004, p. 2.) $)^{6}$.

\footnotetext{
${ }^{6}$ El resaltado es personal.
} 
La construcción del conocimiento es un proceso, en el cual las personas son activas partícipes de su construcción y, por lo tanto, una computadora por sí sola, no necesariamente facilita ni promueve la construcción de conocimientos. Esto es aún más delicado en las primeras edades, en que el uso de los sentidos es trascendental.

\section{6. ¿Una sola visión de mundo?...}

Las distintas visiones de mundo se encuentran implícitas en los diferentes esfuerzos realizados para introducir la tecnología en las aulas y, en los cuales, se presentan las contradicciones normales de un cambio de época. Por ejemplo, la FOD (MIDEPLAN, 2003) concentró, en sus inicios, sus esfuerzos en la capacitación y en dotación de equipos a las escuelas (visión mecánica) ${ }^{7}$ y en impactar efectivamente el desarrollo personal e intelectual de los niños y las niñas (visión holística). Por su parte Fernández (2004, s.p.) define a "la informática-Internet como un medio más que la escuela puede incorporar en su seno" (visión mecánica), y Quesada (2001, p. 7) que plantea que "la escuela es una instancia que debe formar no solo para acceder a un puesto laboral (visión económica), sino para que las personas puedan generar cambios en las condiciones de su propia existencia" (visión holística).

Vivir en un cambio de época significa "vivir en un contexto contradictorio...vivir en una situación más compleja que si viviéramos en la época anterior o en la nueva época. La contradicción y la complejidad se dan porque vivimos entre dos épocas y en ese contexto es que se dan las diferentes expresiones contradictorias. Es en este contexto donde se generan visiones, enfoques, modelos y paradigmas para construir el futuro y es en él donde los educadores habrán de educar para esa sociedad en transición, para la economía que habrá de asumirse y para la política de la nueva época. Es en este contexto donde habrá de enseñarse cómo usar la nueva tecnología y cómo generar pensamiento. Este es el contexto donde se habrá de capacitar para la creación de estrategias, para el nuevo conocimiento, para la innovación, para crear y para construir el futuro de las generaciones jóvenes. Se trata de un contexto movedizo donde la

\footnotetext{
${ }^{7}$ El texto en paréntesis muestra la visión de mundo dominante que la autora observa en el ejemplo mencionado.
} 
educación habrá de pensarse como práctica y como teoría de esa práctica, como conceptuación pedagógica. (Ordóñez, 2004, p. 11)

En esta contradicción continua, es importante tener claro que asumir una visión de mundo específica, no implica dejar de tomar en cuenta las otras dos, sino más bien entender la realidad, grupal e individual, desde esta perspectiva para saber reconocer cuál es la visión de mundo predominante en cada una de nuestras acciones, asumir una posición y actuar coherentemente con ella.

Además, en la época de la Información que nos aventuramos como planeta y en la cual la información (en todas sus formas) será poder, es esencial que nuestros niños y niñas tengan acceso a las herramientas que faciliten no solo el uso de la información, sino también la organización de la misma, así como la propia producción. Por lo tanto, no existe la menor duda de la necesidad de la presencia de las diferentes tecnologías en las aulas. La cuestión es para qué utilizar las tecnologías en las aulas, sobre todo cuando "...tenemos claro lo que ha sido la Revolución Industrial, pero no tenemos clara la época emergente" (Ordoñez, 2004, p. 10).

La convocatoria de la Tercera Revolución, en el caso de Costa Rica, se centra en buscar el tipo de cualificación, necesaria para estar incluidos en los procesos, que se experimentan en forma diferencial en cada una de las regiones o Estado-nación. Esta nueva cualificación va más allá de habilidades y conocimientos concretos, etc. como se anotó, que satisfaga las nuevas demandas del mercado. Es una opción que se oriente a que las personas entiendan, piensen y hablen de aquello que pueden hacer. (Quesada, 2001, p. 7)

En el ámbito educativo, mucho se ha hablado de la informática educativa, aunque la discusión acerca del concepto de era digital, la visión dominante en este concepto, el enfoque pedagógico pertinente es todavía un pendiente. Da la impresión de que los programas de informática educativa, aún cuando en su discurso se manifiesta como prioridad a la persona y su proceso de construcción de conocimiento, en la práctica los programas educativos no han considerado el aprendizaje como un proceso activo, ni de mente, ni de "movimiento, curiosidad y exploración" (Chavarría, 2004), agravado con el hecho de que "la 
mayor parte de ellos (programas computacionales) son opacos" y que es "realmente imposible ver los procesos que se llevan a cabo en ellos..." (Papert, 2005).

Como bien lo afirma recientemente Badilla (2005),

Es inútil continuar inoculando el sistema complejo con reformas e innovaciones. Es tan inútil hacerlo, desde el ámbito político-organizacional, como desde el técnicopedagógico, desde la administración o, incluso, desde las bases. El sistema ha alcanzado su equilibrio y no será transformado por intervenciones ajenas, sobre todo, si están, como suele ocurrir, separadas, especializadas y desarticuladas. Es decir, desde una visión mecánica de mundo.

La crisis del sistema escolar se agrandará si los gobiernos y los actores sociales no adoptan medidas creativas de transformación del sistema educativo al tiempo que introducen Internet en las escuelas. El conflicto será inevitable entre la cultura escolar y la cultura Internet (y no tanto por los contenidos, como por los estímulos de cada una en los niños y jóvenes) si se pretende meter Internet en la escuela inmutada e inmutable. En esta escuela, hoy por hoy, no cabe Internet en el sentido enunciado antes. Y si los sistemas educativos se resisten al cambio, a medio plazo la telaraña Internet podría atrapar definitivamente a los sistemas escolares, dejando sumidos en el caos a todos (Fernández, 2004).

En esta época, también hay que recordar más que no hay recetas únicas que se apliquen a todos y todas por igual. Cada institución educativa, cada localidad utilizarán su capacidad de imaginación y de creatividad para desarrollarse, ya sea como pueblo y como personas. Todo apunta a que la tecnología digital se usa en las aulas como una herramienta más; es decir, bajo la metáfora de que el mundo es una máquina, sin poner atención a que se está perdiendo la capacidad creadora y de imaginación que tiene el ser humano.

En torno a la incorporación de la tecnología en el aula, desde un enfoque constructivista, se requiere pensar detenidamente, en primer lugar, el significado de vivir en la época actual dada su complejidad y cambio, en segundo lugar, asumir una visión de mundo para interpretar el significado de la realidad, en tercer lugar desarrollar un determinado enfoque epistemológico coherente con esta visión de mundo y, en cuarto lugar, no hacerlo en forma aislada porque no tendría sentido. 
Ser educador o educadora implica tener una oportunidad para determinar colectivamente, desde cada institución educativa, la visión de mundo relevante para el logro de los fines de la educación costarricense ${ }^{8}$; conlleva detectar mejoras que necesita la comunidad educativa y asumir compromisos ante esas necesidades. Finalmente, junto con el proyecto educativo y curricular, se asume el método mediador en la introducción de las tecnologías en las aulas.

\section{Reflexiones finales}

Vivir en un cambio de época implica grandes desafíos. Empezando por entender el contexto, que es permanentemente cambiante, diverso y exigente, en una era en que el conocimiento practico es esencial para formar parte del engranaje o de las redes existentes. Además exige la redefinición de ideas, mecanismos e instrumentos para influir en la sociedad, considerándola vulnerable, dada la turbulencia del entorno.

Las revoluciones presentes exigen al sistema educativo, en general, y a cada una de las personas que se desenvuelven en el ámbito educativo, en particular, un cambio de paradigmas. Eso significa un cambio en la forma de ver el entorno. Las soluciones a los problemas cotidianos no pueden resolverse bajo las reglas anteriores porque estas ya no son válidas. Es necesario reinventar las reglas, y esto solo puede hacerse en la colectividad y como respuesta a los desafíos del contexto más inmediato, tomando en cuenta la turbulencia mundial.

En el caso de la utilización de las tecnologías digitales esto no es menos simple. ¿Cómo mantener procesos humanizados en la construcción de conocimientos mediante el uso de tecnologías? Una reflexión sobre la introducción de las tecnologías digitales en las aulas, puede darse en relación con los siguientes aspectos:

- Un cambio de época y no una época de cambios.

- Nuestra visión de mundo (holística, mecánica o económica).

${ }^{8}$ En el entendido que todavía sean válidos esos fines. De lo contrario se puede generar propuestas para mejorarlos. Estos fines traen consigo una serie de premisas orientadoras para el logro de los objetivos institucionales. 
- Nuestros actos educativos (sobre todo para docentes), dado que están influenciados directamente por los dos aspectos anteriores.

El sistema educativo costarricense, en los últimos años, se ha ocupado en responder a las demandas sociales preparando a sus estudiantes para ese contexto y ha introducido las computadoras en las aulas y las ha acercado a muchas comunidades. ¿En Costa Rica, luego de 20 años de introducir las computadoras en las aulas, cuál visión de mundo se observa como dominante? ¿Cuál es la actitud con la que los niños y las niñas se acercan a la tecnología? ¿Son ellos y ellas quienes se acomodan a las demandas de la tecnología, o es ésta un recurso para ser adaptado a la satisfacción de sus necesidades e intereses? ¿Con qué tipo de tecnología están en contacto los niños y las niñas de Costa Rica?

Las instituciones preescolares utilizan la tecnología bajo la visión mecánica de mundo. ¿Conocen el cambio de época actual? ¿Conocen las implicaciones de asumir una visión de mundo? ¿Aplican pedagogías coherentes con la visión de mundo con la cual actúan?

Las propuestas del construccionismo y constructivismo son esperanzadoras, porque devuelven a las personas su rol activo en su aprendizaje. Sin embargo, es necesario dirigir la mirada hacia un contexto cambiante y estremecido por movimientos planetarios que afectan indiscutiblemente la cotidianidad.

Afirmar que todos los esfuerzos hechos en materia de informática educativa, han sido en vano sería un gran error. Todos éstos han sido grandiosos y han permitido un acercamiento a la tecnología, a miles de niños, de niñas y adolescentes. Ahora es el momento de replantear las estrategias metodológicas que mejoren lo andado para que se asuma conscientemente una visión de mundo, por lo tanto un paradigma epistemológico y dirigir los esfuerzos en acercar la práctica educativa a este paradigma asumido.

Por lo tanto, parece ser que una reflexión profunda, en torno a lo que significa asumir una visión de mundo y su implicaciones, así como a la introducción de la tecnología digital en ambientes pedagógicos, se hacen esenciales, tanto para hacerlo de una forma coherente con el cumplimiento de los derechos de los niños y de las niñas, como para definir las razones por las cuales la tecnología digital sí puede ser un recurso para los niños y las niñas en el logro de sus metas personales. 


\section{Referencias}

Badilla S., E. (1991). Informática educativa en Costa Rica a partir de 1987. Revista Educación, 15(1): 7 - 17.

Badilla S., E. (1994). Hacia una política de informática educativa en el sistema educativo de Costa Rica. San José, Costa Rica: Departamento de Informática Educativa. Ministerio de Educación Pública.

Badilla S., E. (2005, 10 de abril). El efecto mariposa. La Nación, Sección Opinión.

Badilla S., E. y Chacón M., A. (2004). Construccionismo: Objetos para pensar, entidades públicas y micromundos. Revista Electrónica: "Actualidades investigativas en educación", 4(1) Año 2004. Recuperado el 14 de marzo del 2005, de: http://revista.inie.ucr.ac.cr

Brown, A. L., Kane, M. J. y Song, C. (1989). Analogical transfer in young children: analogies as tools for communication and exposition. Applied Cognitive Psychologie.

Castells, M. (2005a). Biografía, obras y algunos artículos. Recuperado el 27 de mayo del 2005, de http://www.castellsarticulos.html

Castells, M (2005b). La dimensión cultural de Internet. Recuperado el 27 de mayo del 2005, de: http://www.Castellsyladimensiónculturalinternet.htm .

Chavarría, M. C. (1993). Tendencias políticas de la educación preescolar. San José. Costa Rica: Editorial de la Universidad de Costa Rica.

Chavarría, M. C. (2004) Comunicación personal. Centro Infantil Laboratorio, Universidad de Costa Rica.

Costa Rica, Ministerio de Planificación (MIDEPLAN). (2003). Plan Nacional. Recuperado el 20 enero de 2005, de http://www.mideplan.go.cr/odt/Plan\%20Nacional/Capital\%20Humano/Educacion/cobe rtura.htm

De Souza S., J. (2001). ¿Una época de cambios o un cambio de época? Elementos de referencia para interpretar las contradicciones del momento actual. Publicación mensual del Instituto Científico de Culturas Indígenas. Año 3, No. 25, abril del 2001. Fundación ISNAR, San José, Costa Rica.

De Souza S., J. (2003a) Conferencia: "La academia del Siglo XXI y los programas de Acción Social". Actividad organizada por la Vicerrectoría de Acción Social y realizada el 23 de abril en el Auditorio de la Facultad de Agronomía, Universidad de Costa Rica. San José, Costa Rica.

De Souza S., J. (2003b) Exposición: "Pedagogías en conflicto para la educación en la universidad del siglo XXI". Primera jornada de intercambio de experiencias innovadoras en la educación universitaria. Actividad organizada por el Consejo 
Nacional de Rectores y las Vicerrectorías de Vida Estudiantil y realizada en el CENAT el 28 de octubre. San José, Costa Rica.

Fernández, J. A. (2004). La telaraña internet y la escuela. Recuperado el 11 de febrero 2005, de http://www.tremn.org/ponenciajaff\%20educaci\%C3\%B3n.doc

Fernández C., R. (2001) Definición de tecnologías de la información. Glosario básico inglés-español para usuarios de Internet. Versión HTML 4.0 (julio 2001) de la cuarta edición impresa (mayo 2001). Recuperado el 15 de junio de 2005, de http://www.ati.es/novatica/glosario/glosario internet.html.

García F., J. (2001). Supuestos epistemológicos que subyacen a la innovación educativa. Revista Electrónica "Actualidades investigativas en educación”, 1(1), Año 2001. Recuperado el 20 de febrero de 2004, de: http://revista.inie.ucr.ac.cr.

García F., J. (1997). La Educación desde la postmodernidad: perspectivas culturales y pedagógicas de la informática educativa. Revista de Filosofía de la Universidad de Costa Rica, 35(85), $37-48$.

García F., J. (2003). El potencial tecnológico y el ambiente de aprendizaje con recursos tecnológicos: Informáticos, comunicativos y de multimedia. Una reflexión epistemológica y pedagógica. Revista Electrónica "Actualidades investigativas en educación", 3(1), Año 2003. Recuperado el 20 de febrero del 2005, de: http://revista.inie.ucr.ac.cr

García F., J.; Murillo V., R.; Zúñiga C., M. (1992). Mi experiencia con el programa de Informática Educativa MEP - FOD. Impacto del programa en una Escuela de Zona Rural. San José. Costa Rica: División Planeamiento y Desarrollo Educativo (CENADI). Ministerio de Educación Pública.

González F., J. (1991). La efectividad de un programa LOGO interactivo para desarrollar habilidades de programación en los niños. Revista Educación de la Universidad de Costa Rica, 15(1), pp. 31-37.

González, G., V. (2003). Proyecto: “Informática educativa en el Centro Infantil Laboratorio". Vicerrectoría de Acción Social, Universidad de Costa Rica. Comunicación personal con docentes del centro.

Gurdián F., Alicia. (2001). Las nuevas tecnologías de la información y de la comunicación en la educación universitaria. Revista Electrónica "Actualidades Investigativas en Educación", 1(1), Año 2001. Recuperado el 20 de febrero del 2005, de: http://revista.inie.ucr.ac.cr

Hurlock, E. (1989). Desarrollo del niño. Segunda Edición. México: Editorial Mc Graw-Hill.

Leiva O., J. y Leiva O., J. (2003). Aplicación de nuevos métodos didácticos en el aula para asignaturas de computación: Utilización de un software cliente/servidor. Revista Electrónica "Actualidades investigativas en educación”, 3(2), Año 2003. Recuperado el 14 de marzo del 2005, de: http://revista.inie.ucr.ac.cr 
Mata, A. (2003). Conferencia: "Construcción de la identidad personal durante la primera infancia". Psicóloga "Programa de la mano", Gobierno de Costa Rica. Realizada el 23 de junio en el Auditorio de la Facultad de Educación, Universidad de Costa Rica.

Meoño, R. (2003). Vinculación remunerada con el sector externo: un reto para la Facultad de Ciencias Sociales de la Universidad de Costa Rica. Tesis para optar al grado de Maestría en Trabajo Social. Universidad de Costa Rica.

Mikhak, B. y Badilla S., E. (2003a). Conferencia: "Estado del arte de las tecnologías digitales". Investigadores del Instituto Tecnológico de Massachussets. Realizada el 26 de mayo del 2003 en el Auditorio de la Facultad de Ingeniería, Universidad de Costa Rica.

Mikhak, B. y Badilla S., E. (2003b). Taller: "acciones, reflexiones e ideas poderosas". Investigadores del Instituto Tecnológico de Massachussets. Realizado en el Campus Walter Kissling Gam, INCAE. San José, Costa Rica.

Minsky; M. (1986). La sociedad de la mente. La inteligencia humana a la luz de la inteligencia artificial. Buenos Aires, Argentina: Ediciones Galápago.

Novak, J. Y Gowin, B. (1984). Aprendiendo a aprender. Barcelona, España: Ediciones Martínez Roca.

Ordóñez, J. (2004). Ciencia, tecnología y ser humano en el contexto de cambio de época. Universidad de Costa Rica. Congreso Humanidades, Colombia. Recuperado el 20 enero del 2005, de http://www.utem.cl/congresohumanidades/ponencia/mesa\%202/j ordon.html

Ordóñez, J. (2005). Los retos de la sociedad del conocimiento en la pedagogía universitaria. Conferencia en el Departamento de Docencia Universitaria de la Escuela de Formación Docente. Facultad de Educación, Universidad de Costa Rica. Actividad realizada el jueves 23 de junio del 2005 en la Sede Rodrigo Facio.

Papert, S. (1995). La máquina de los niños. Replantearse la educación en la era de los ordenadores. Barcelona, España: Ediciones Paidós Ibérica.

Papert, S. (2005). La familia conectada. Superando la brecha de la generación digital. Extracto: Una historia de aprendizaje. Recuperado el 24 de marzo del 2005, de http://www.connectedfamily.com/

Perfil - Fundación Omar Dengo. Recuperado el 20de enero de 2005, de www.fod.org

Pichs, R. (2005). Tecnologías de la información y las comunicaciones y orden económico mundial. Introducción. La Habana, Cuba: Centro de Investigación de la Economía. Recuperado el 15 de junio del 2005, de http://www.definicion.org/tecnologias-de-la-informacionTecnologías

Quesada S., Rolando (2001). Los "machetes" en la tercera revolución. Repensando la Educación. Revista Electrónica "Actualidades investigativas en educación", 1(1), Año 2001. Recuperado el 20 de febrero del 2005, de: http://revista.inie.ucr.ac.cr Volumen 5, Número 1, Año 200523 
Red Universitaria en Primera Infancia. PRIDENA, Universidad de Costa Rica. (2003). II Simposio sobre los derechos de la Niñez y la Adolescencia. Realizado el 8, 9 y 10 de septiembre en la Universidad de Costa Rica. San José, Costa Rica: La Red.

Zamora, A. (1997). Ética y creatividad tecnológica. Revista de Filosofía de la Universidad de Costa Rica, 35(85), 107 - 113.

Zúñiga C., M. (1994). Del constructivismo al construccionismo. Modelos de Aprendizaje II. San José, Costa Rica: Ministerio de Educación Pública. Recuperado el 10 de octubre del 2003, de http://www.mep.go.cr/educación/construccionismo

Zúñiga C., M.; García F., J. Y Murillo V., R. (1992). Mi experiencia con el programa de Informática Educativa MEP - FOD. Impacto del Programa en una escuela de zona rural. Informe de Investigación cualitativa. San José, Costa Rica: División de Planeamiento y Desarrollo Educativo (CENADI). 